\title{
Conflict Mediation and Resolution: the contribution of social psychology
}

\section{Tania Ogay}

To cite this article: Tania Ogay (1998) Conflict Mediation and Resolution: the contribution of social psychology, European Journal of Intercultural studies, 9:3, 269-277, DOI: 10.1080/0952391980090304

To link to this article: https://doi.org/10.1080/0952391980090304

曲 Published online: 28 Jul 2006.

Submit your article to this journal

Џ Article views: 55

Q View related articles $\sqsubset$

4 Citing articles: 1 View citing articles ๘ 


\section{Conflict Mediation and Resolution: the contribution of social psychology}

\section{TANIA OgaY}

ABSTRACT Following an already widespread movement in North America, networks of mediators are being established in Europe. These mediators offer their services to the civil community in order to solve minor conflicts through negotiation rather than through penal action. By presenting the contribution of social psychology to conflict mediation, this article asserts the necessity of adopting a constructivist vision of conflict, by which the mediator will try to reconstitute the different perspectives of the actors vis-à-vis the conflict situation and then negotiate a common mode of interaction which can be accepted by all the parties.

RÉSUMÉ Suivant un mouvement déjà bien développé en Amérique du Nord, des réseaux de médiateurs se mettent en place en Europe, proposant à la communauté civile de résoudre des conflits mineurs par une voie négociée plutôt que par la voie pénale. En présentant les apports de la psychologie sociale pour la médiation des conflits, cet article met en lumière la nécessité d'adopter une vision constructiviste du conflit, qui cherche à reconstituer les differentes perspectives des acteurs sur la situation de conflit avant de négocier un mode commun d'interaction qui soit acceptable par tous.

\section{Human Relations, Conflict and Social Psychology}

When we think of human relations, although we would prefer to see them in terms of mutual understanding and harmony, everyday life reminds us of the prevalence of conflict. As soon as there are social relations, there is potential conflict. One could even say that conflict is the essence of social relations and that all our communication behaviours aim at preventing or solving conflict. Nowadays, conflict mediation has become a growing concern, especially for local authorities preoccupied by the rise of violence in urban communities. Already widespread in North America, networks of mediators are now developing in Europe as well. For example, a "Maison de la Médiation" was created in March 1997 in Geneva. The mediator intervenes in the conflict as an impartial third party. His or her objective is to set up a process where the parties in conflict can exchange their viewpoints and then search for a negotiated solution (Bonafe-Schmitt, 1993). To be fruitful, the mediation will have to take into consideration not only the explicit object of the conflict, but also its socio-psychological context and try to define the different stakes in the situation for the actors (power, social recognition, etc.). Mediators will find in social 
psychology, a discipline studying the relations between the individual and society, many useful insights that will help them to situate the conflict in the perspectives of the actors, a necessary stage before negotiating a common solution to the conflict. Especially the contribution of social cognition will help the mediator to understand how individuals perceive their social environment (and, therefore, a conflict situation). The social psychology of intergroup relations will provide very useful conceptual tools to analyse intergroup conflicts and discriminatory behaviours, which will help the mediator to understand the mechanisms of the social stakes of any conflict situation, even when the conflict seems to involve only individuals.

\section{Social Cognition: from a unique and objective reality to diverse and con- structed realities}

\section{The Myth of an Objective and Directly Observable Reality}

Our Western societies are still very much impregnated with the Age of the Enlightenment and its faith in science and reason. We tend to think that what we see exists in itself and in an objective way, reality being external to the individual who observes it (Pourtois \& Desmet, 1988). This conception of the world, which is called "positivism" in science, considers that reality corresponds to facts that can be observed objectively, and even measured and quantified. A positivist approach to a conflict would consist of an "objective" analysis of the situation, as close as possible to real and known facts, cautiously pushing aside the perceptions, emotions and motivations of the conflict's actors. These subjective elements are considered to disturb the correct assessment of the situation.

But is reality really objective? Is reality made up only of observable facts? And can facts be separated from the perceptions and emotions of the actors of the situation? Already in the 18 th century Kant criticized the objectivity of our perception of "reality", as he distinguished between our perceptions (the phenomena) and the things per se. Reality is not directly accessible, we perceive reality through what the philosopher called the $a$ priori frames of our understanding. Thus, an analysis limited to the "real facts" of a conflict is insufficient, because the conflict does not exist in itself alone but through the subjective perceptions of the protagonists (which include also the mediators, who also have their subjectivity, even if they should strive towards impartiality). Even if this was not his project (Kant's ambition was to reach the knowledge of the essence of things, beyond phenomena), one can say that Kant had established the basis for the "constructivist" approach that developed in the humanities during the second half of our century. The constructivist approach considers our perception of reality as a product of mental construction (Lecomte, 1997). A constructivist approach of conflict will aim at making explicit the $a$ priori frames of understanding of the conflict's actors, making them aware of the relativity of their perception of the situation, so that they understand that their reality is not necessarily the reality of the other (Watzlawick, 1978). Becoming aware of the relativity of the way we perceive a situation constitutes the first stage before negotiating a mode of interaction that can be accepted by everyone. 


\section{Biases in Social Perception}

According to the constructivist approach, the perception that a social actor has of any social situation is not a pure and true reflection of facts but a mental construction influenced by his or her own personal history, motivations towards the situation, etc. Social cognition research has studied the psychosocial processes operating in social perception (Pendry et al., 1994). Analogous to sensory perception, three phases can be defined during which constructions and reconstructions of social perception occur, which explains that two social actors may have diametrically opposed views of the same situation.

The selection of information. Confronted with the infinite variety of data coming from one's environment, one is forced to select information by filtering the data and retaining only a limited amount of it. We will take into account certain data (that which we want to see), while we will ignore others (that which we do not want to see). This, of course has consequences for our vision of "reality". Certain data are retained more easily than other data, either because such information is more easily accessible and does not demand too much effort to be collected (this is the case, for example, when processing rumour or gossip) or because the information will attract one's attention because of its unusual or salient nature (for example the only African family on the block, on which the entire neighbourhood focuses its attention).

Our perception of the world is organized into categories (which we build through our personal history, but which are also transmitted to us by our social and cultural environment). Our categories help us to simplify our environment so that it becomes more easily predictable and manageable. If they allow us to impose some kind of order in the abundance of data coming our way, categories also allow us to compensate for a lack of information, since they allow us to apply to one object the characteristics of the category to which this object belongs (or more precisely, the characteristics of the category to which we think that the object belongs), which is the very definition of a stereotype. Our system of categories orients the way we select information, it organizes our selection of information, but it also makes it rigid, leading us to ignore the information that does not fit into the existing categories. Furthermore, categorization leads us to integrate apparently fitting data without further questioning, which explains the perpetuation of stereotypes.

Thus, with this brief description of the first phase of social perception, one understands that a conflict can emerge from a situation in which each actor has perceived "reality" in ways that can be very different, individuals assigning more importance to certain information which corresponds to their categories and expectancies.

The interpretation of information. After having selected the information, we try to interpret it, i.e. we try to attach meaning to it. This search for the meaning of observed behaviours has been called "social attribution" by social psychologists (Deschamps \& Beauvois, 1994; Deschamps \& Clémence, 1990). If we can interpret the information, if we can attribute meaning to a behaviour, we can explain the 
cause of the behaviour and, above all, we can predict the future of the interaction. But to discover the cause of a behaviour is not an easy task, because social interactions are nothing else than chains of behaviours which are all responses to other behaviours, and these themselves cause other behaviours. It is then difficult to determine which behaviour is the cause and which one is the effect. It becomes all the more difficult since the social actors, as Watzlawick et al. (1972) remind us, do not share the same perception of this chain of behaviours (this is the eternal debate among children about who started a conflict, but it is not very different in war situations between States!).

Research on social attribution has shown that behavioural attributions will not depend as much on the behaviour itself, but on the interpretation grid applied to it, and different readings are always possible. The conclusions we draw from our observations are not always relevant and there are numerous distortions between our judgement and "reality".

- When we try to attach a meaning to someone's behaviour, we base our judgement mainly on the first information available and attach far less importance to the information that comes afterwards. One can see how important it is that the first moments of an interaction be successful or that the reputation which precedes us be positive!

- It has also been demonstrated that many attributions are based on a very limited amount of information (contenting oneself with the first apparently satisfying explanation, without wondering if other explanations are also possible) or, worse, on irrelevant data (like, for example, evaluating someone's intelligence on the basis of physical appearance).

- Research on attribution has also pointed to an egocentric and ethnocentric bias that we have. We tend to attribute meaning to the behaviour of others using our own frame of reference, our own norms of behaviour, which can be very different from those of the other person's sociocultural background.

- In our Western societies, which follow an individualistic orientation, social psychologists have described what they have called the "fundamental attribution error" (Ross, 1977): our tendency to prefer explanations of internal causality (the personality of the individual his competencies) to explanations of external causality (the context, the conditions of the environment). Take the example of a typical neighbourhood conflict: exasperated by the very loud music coming out of our neighbour's flat, we would tend to explain the nuisance by the bad manners of our uneducated neighbour rather than by the walls' thinness due to cheap construction.

- Things become even more complicated when we deal with what has been called the "ultimate attribution error" (Pettigrew, 1979), which can be schematized as in Table 1 .

A socially positively valued behaviour (for example success in an exam) of a member of our own in-group will be attributed to an internal cause (the intelligence of this person, a typical quality of our in-group as well), while the same behaviour elicited by someone from another group will be more willingly attributed to an 
TABLE 1.

Socially positively valued behaviour
Socially negatively valued behaviour
Of in-group member

Of out-group member
Internal attribution

External attribution
External attribution

Internal attribution

external cause (the fact that the exam was so easy that anyone could pass it). Conversely, a socially negatively valued behaviour (failing an exam) will find an external attribution for someone from our in-group (the exam was badly conceived) and an internal attribution for someone from an out-group (he was not clever enough, as they all tend to be in this group). If we consider again our example of a neighbourhood conflict, the "ultimate attribution error" should draw the mediator's attention to the fact that the cause of the problem will be more easily attributed to the neighbour's personality if the individual is seen as belonging to a different social group, while if the two neighbours recognize themselves as members of the same social group, they will more readily look for the cause of their problem in their living conditions. Thus, the same behaviour will not be explained in the same way, depending on the social and cultural group membership of its author. One should not forget that these schemes of causality go beyond the individual level and that they are a reflection of social practices and express the conflicts and the hierarchical systems of social life.

The memorization of information. The memorization of the information which has been perceived and interpreted is the occasion for a third reconstruction of "reality": all the information is not processed equally while it makes its way into memory, the degree of fidelity between memory and "reality" nor in the process of recall to consciousness.

\section{Social Psychology of Intergroup Relations: understanding the psychosocial dimension of conflict}

\section{The Concern about Favouring One's In-group and Maintaining the Organization of Social Space}

Social psychologists who have studied the relations between social groups have tried to explain behaviours such as those described above within the framework of the "ultimate attribution error": why is it that we observe so often that people favour their in-group and discriminate against others? How and in what ways is the behaviour of individuals influenced by their membership in social groups? This research (for reviews see Bourhis et al., 1994; Hewstone \& Jaspars, 1990) has pointed to the difficulty, or even the impossibility, of clearly separating the interpersonal level from the intergroup level. Let us consider for example our neighbourhood conflict. It apparently seems to concern two individuals only. We see upon 
further inspection that the conflict is not only between $\mathrm{Mr} \mathrm{X}$ and Mrs $\mathrm{Y}$, but through them also the conflict between the social group of the older versus the younger generation or between the social group of the indigenous population and that of the foreigners, with all the social representations that this implies. A conflict between two individuals is not taking place on the interindividual dimension only: the memberships in social groups also play their part in the conflict, even if the actors are unaware of it. Thus, when a mediator intervenes in a conflict situation, he or she intervenes not only in a relation between two individuals, but also in a relation between social groups (Azzi, 1994; Touzard, 1972).

The Social Identity Theory of Tajfel (1978) explains the psychological stakes associated with intergroup relations. Tajfel showed how important it is for any individual to feel that he or she belongs to valued social groups. This feeling provides the individual with a positive social identity, essential to self-esteem. Now, in order to know if the group with which one identifies oneself is valued, the individuals compare their group's situation with the situation of other groups. And, in order to be sure that the comparison will be favourable to one's own group, the individual will tend to favour his or her group and deprecate or even discriminate against the other groups. This need for a positive social identity is one of the explanations given by social psychologists for intergroup discriminatory behaviours. They have showed that a conflict does not need objective reasons (like scarce resources) to appear; the need for a positive social identity can explain numerous conflicts which seem to have no objective reason at all. To solve them, it is necessary to pay attention to this justified need and look for a way to satisfy it, but not at the expense of others.

\section{In Search of Strategies to Improve Intergroup Relations}

The improvement of intergroup relations was precisely the goal of a series of research projects that looked at different possible change strategies, assessing their strengths and weaknesses. A very common view contends that intergroup conflict arises out of mutual ignorance and that if the groups would come into contact with each other, they would get to know each other and would not fear each other anymore. But research on the "intergroup contact hypothesis" (for a review see Corneille, 1994) showed that simple contact can even make things worse and that there are important conditions that need to be met, like proposing a cooperative activity to the groups and asking them to arrive at common goals. But another crucial condition for the improvement of intergroup relations through contact is that this cooperative activity be successful, otherwise the failure will be attributed to the other group, following the "ultimate attribution error" scheme described above.

Other strategies have been tried. One could cite, for example, the socio-cognitive method of crossed categorization (Deschamps \& Doise, 1978). The mediator intervenes in the social categorization process, trying to make the individuals abandon their dichotomized representation of the social world (Us and Them) for a more differentiated representation, with multiple categories crossing each other: 
for example, a xenophobic individual would see that if a person $\mathrm{X}$ is a member of the disliked group of the foreigners this person $\mathrm{X}$ is also member of the same professional group as oneself. Such individuals should then revise their negative judgments because they cannot discriminate against someone from their own group. But to be successful, this strategy requires that both categories be equally salient for the individual. And one should not use this strategy in situations where it could lead to double categorization ("Not only is he a foreigner but he is one of these intellectuals too")!

\section{Conflict as a Communication and Cultural Practice}

We have looked for the intersection where cognition and the social psychology of intergroup relations connect and relate to conflict mediation. But to be complete and to get closer to the complexity of social conflict, we should also consider the communication sciences (and here too, their interpersonal, intergroup and intercultural dimensions). Conflicts are expressed in the communication process and are solved through communication. Communication sciences for example show us how a conflict can appear due to the diversity of the codes being used by the actors of communication (Gudykunst \& Kim, 1992). The expressions of our behaviours (verbal and non-verbal) are very conventional, they follow more or less explicit codes. Our various enculturations, socializations and personal histories lead us not to use the same codes in our communication, when expressing ourselves (the encoding of information), as well as when we interpret the messages that we perceive (the decoding of information). Depending on the individuals and the social and cultural contexts, the same message can be expressed through different behaviours and one single behaviour can take on different meanings (for example, in some cultures an up and down movement with the head indicates that one agrees with one's interlocutor, while in other cultures this same movement indicates disagreement). It is not difficult to imagine the conflicts that can emerge only because one did not succeed in interpreting correctly the verbal and non-verbal behaviours of one's counterpart, attributing them with a meaning different from the author's intentions.

The intercultural dimension should definitely not be left out in the analysis of conflict situations. This dimension is all the more important since conflict resolution in itself is a social and cultural practice, which doesn't follow the same codes and rules everywhere (Ting-Toomey, 1988). Thus, our Western cultures favour a solution-oriented resolution of conflict, with a direct confrontation of the parties who openly discuss the possible alternatives in order to reach a consensus. But other cultures prefer very different modes of conflict resolution, for example avoiding direct confrontation, using go-betweens and deliberately non-explicit communication, in which the non-verbal can have more importance than the verbal messages. Before offering his mediation, the mediator should definitely pay attention to the cultural backgrounds of the actors of the conflict and offer a conflict resolution style that can be accepted by all the parties. Otherwise the mediator would run the risk of creating a "metaconflict", i.e. a conflict about the conflict! 


\section{Concluding Remarks}

The main contribution of social psychology to the analysis of conflict may be that it introduces us to the ambiguity of the social world, warning us against our perceptions (as actors of the conflict and as a mediator). What I see is not necessarily what "is"; the other actors in the situation see things differently than I do; in the situation there are explicit but above all implicit stakes which have to be decoded. To understand each other, we have to be empathic (try to imagine and understand the other's viewpoint) and metacommunicate, i.e. communicate about our communication (Watzlawick et al. 1972). The mediator's role should be to first make the actors' different perspectives on the conflict visible. By taking into account their psychological, social and cultural backgrounds, it would then become possible to understand how and why the actors perceived the situation as they do. In a second stage, the mediator can help the actors to negotiate a common interaction mode.

Address for correspondence: Université de Genève, FPSE, 9, route de Drize, CH-1227 Carouge, Switzerland. E-mail: ogay@fapse.unige.ch

\section{References}

AzzI, A. (1994) La dynamique des conflicts intergroupes et les modes de résolution de conflits. In: Bourhis, R.Y. \& Leyens, J.-P. (Eds) Stéréotypes, Discrimination et Relations Intergroupes. Liege: Mardaga, pp. 293-319.

BonafÉ-SChMiTT, J.-P. (1993) La ou les médiations des conflits. Migrants-Formation, 2, pp. 1135.

Bourhis, R.Y., GaGnon, A. \& Moise, L.C. (1994) Discrimination et relations intergroupes. In: BourhIS, R.Y. \& LEyens, J.-P. (Eds) Stéréotypes, Discrimination et Relations Intergroupes. Liège: Mardaga pp. 167-200.

CoRneille, O. (1994) Le contact comme mode de résolution du conflit intergroupes: une hypothèse toujours bien vivante. Cahiers Internationaux de Psychologie Sociale, 23, pp. 40-60.

Deschamps, J.-C. \& Beauvois, J.-L. (1994) Attributions intergroupes. In: BouRHIS, R.Y. \& LEYENS, J.-P. (Eds) Stéréotypes, Discrimination et Relations Intergroupes. Liège: Mardaga, pp. 97-126.

Deschamps, J.-C. \& ClÉmence, A. (1990) La notion d'attribution en psychologie sociale. In: Deschamps, J.-C. \& Clémence, A. (Eds) L'attribution. Causalité et Explication au Quotidien Neuchâtel, Paris: Delachaux \& Niestlé, pp. 17-43.

Deschamps, J.-C. \& Doise, W. (1978) Crossed category memberships in intergroup relations. In: TAJFeL, H.J. (Ed.) Differentiation between Social Groups. London: Academic Press.

Gudykunst, W.B. \& KIM, Y.Y. (1992) Communicating with strangers. An approach to intercultural communication (2nd edn). New York: McGraw-Hill.

HEwSTONE, M. \& JASPARS, J.M.F. (1990) Relations intergroupes et processus d'attribution. In: Deschamps, J.-C. \& Clémence, A. (Eds) L'attribution. Causalité et explication au Quotidien Neuchâtel, Paris: Delachaux \& Niestlé, pp. 199-246.

Lecomte, J. (1997) La construction de la réalité. Sciences Humaines, 71, pp. 20-25.

Pendry, L.F., Macrae, C.N. \& Hewstone, M. (1994) Réflexions sur autrui: une approche sociocognitive. In: Moscovici, S. (Ed.) Psychologie Sociale des Relations à Autrui. Paris: Nathan Université, pp. 181-207.

PetTigrew, T.F. (1979) The ultimate attribution: extending Allport's cognitive analysis of prejudice. Personality and Social Psychology Bulletin, 5, pp. 461-476. 
Pourtols, J.-P. \& Desmet, H. (1988) Ispistémologie et Instrumentation en Sciences Humaines. Liège, Bruxelles: Pierre Mardaga.

Ross, L. (1977) The intuitive psychologist and his shortcoming. In: Berkowitz, L. (Ed.) Advances in Experimental Social Psychology, Vol. 10 New York: Academic Press, pp. 173220.

Tajfel, H. (1978) Differentiation between Social Groups. London: Academic Press.

TING-ToOmeY, S. (1994) Managing intercultural conflicts effectively. In: Samovar, L.A. \& PorTer, R.E. (Eds) Intercultural Communication. $A$ reader, 7th Edn. Belmont CA: Wadsworth, pp. 360-372.

Touzard, H. (1972) La Médiation et la Résolution des Conflits. Paris: PUF.

Watzlawick, P. (1978) La Réalité de la Réalité. Confusion, désinformation, communication (trans. Roskis, E.). Original title: How Real is Real? Communication, disinformation, confusion (1976). New York: Random House).

WATZlawick, P., BeAvin, J.H. \& JACKSON, D.D. (1972) Une Logique de la Communication (trans. Morche, J.). Original title: Pragmatics of Human Communication: a study of interactional patterns pathologies and paradoxes (1967). New York: W.W. Norton \& Company. 